\title{
Wenn Frauen Arzt sind, sind Arzt Frauen - von frühen Irrungen
}

\section{Enrico Danieli}

Dr. med., Facharzt für Allgemeine Innere Medizin, Mitglied FMH

Dies alles war damals ein wenig kompliziert, und, da ich mit dem Verstand, der mir zur Verfügung stand, die Situation, die mich beschäftigte, nicht entschlüsseln konnte, verhedderte ich mich umso mehr - und oft umso lustiger für die anderen - in zweideutige Fragen oder Aussagen. Das alles begann so: Die Arzt Frau, die in unserem Haus wohnte und noch vor meiner Zeit einen Arzt zum Mann hatte, danach aber allein blieb und ihrem Beruf als Bibliothekarin wieder nachging, wurde stets mit «die Frau des Arztes» oder kürzer mit «Arztfrau» bezeichnet. Das kam mir ein wenig seltsam vor, weil sie den Doktor, den sie gar nicht mehr hatte, doch noch hatte. Ging mein Vater zum Arzt, ging er zum Hausarzt. Zu einem Arzt des oder unseres Hauses. Danach fragte ich am Mittagstisch: «Geht es dem Haus nicht gut?» Mit Verzögerung setzte das Lachen ein. Das sei nicht, wurde mir erklärt, der Arzt des Hauses sondern des Vaters Hausarzt. Das verstand ich nicht, der Vater war doch kein Haus. Aber das behielt ich für mich. Ausgelacht werden (wie in jener Zeit oft) ist, wie mit Splittermunition beschossen werden: Verwundungen bleiben zurück. Und die nächste, grosse Verwirrung folgte. Häufig hatte meine Mutter in jener Zeit einen speziellen Arzt aufzusuchen. Der hiess Frauen Arzt. Oder, wie ich es mir zurechtlegte, Frau Arzt. Ein Arzt, der eine Frau ist, nein, besser: eine Frau, die ein Mann ist. Die Heiterkeit, die meine entsprechenden Aussagen auslösten, schmerzten mich. Ich verstand es nicht besser, doch niemand wollte Erklärungen geben. Oder, genauso wie die Nachbarin, eine Frau mit einem Arzt als Mann, den es nicht gibt. Ja, das war auch möglich. Oder bedeutete Frauen Arzt, dass mehrere Frauen ein Arzt sind? Wiederum seltsam, das schon. Etwas war mir unheimlich, doch ich konnte es nicht in Worte fassen. Und warum gab es keinen Mann Arzt? Weil alle Ärzte Männer sind, braucht es keine Männer Arzt. Wenn aber eine Frau Arzt ist, dann, wegen der Rarität, musste dies entsprechend meiner nicht ausgereiften Logik bekanntgegeben werden. Ich hatte tatsächlich ein Durcheinander mit diesen Dingen in meinem Kopf, das mich bedrängte, das ich nicht verstand und das zu entschlüsseln mir nicht gelang. Dass dann der Frau Arzt meiner Mutter Herr Doktor Wiederkehr hiess, gab mir noch mehr Gelegenheit, mich in meinen wiederkehren- den Gedanken zu verlieren. Ich verstand nicht nur dieses mit den Frauen und Arzt nicht, sondern - vielleicht als Folge davon - auch vieles andere. (Wegen meines seidiggelockten Haares durfte ich dieses nackenlang tragen, was immer wieder zur Frage führte, ob ich denn ein Mädchen sei: überdrüssig der steten gleichen Frage und mit einer für mich, der ich das "r» in meinem Namen nicht beherrschte, nachvollziehbaren Reaktion, antwortete ich laut und bestimmt: Anna - natürlich war das falsch, aber gleichzeitig ein Akt von Befreiung in diesem ganzen Mann-Frau-Durcheinander.) Nicht nur die Mutter benötigte in jener Zeit der Frauen Arzt Hilfe, auch ich, wegen meiner häufigen Anginen mit Gelenkschmerzen, brauchte den Arzt, selbstverständlich den Kinderarzt. Sind denn, fragte ich in meinem Bett liegend, nur Kinder der Arzt für Kinder? (Ein Gedanke, der mir gefiel, und der mir nachvollziehbar schien.) Jetzt wurde ich ausgelacht, das Fieber gemessen, und dieses war der Grund meiner Irrungen. Der Kinderarzt kam wegen meines hohen Fiebers nach Hause. Dann war er, im Grunde genommen,

Meine Verabschiedung, "vielen Dank Frauen Arzt Doktor Herr Mann", meine gleichzeitige Frage, ob Frau Doktor Mann mehr ein Mann sei, löste lautes Lachen aus.

auch Arzt des Hauses? Hatte ich nun einen Hausarzt? Doch das behielt ich besser für mich. Vorangehend wurde mir nahegelegt, den Kinderarzt freundlich zu begrüssen. Doktor Mann sei der Name. Dann, der Kinderarzt kam gegen Mitte der Nacht, wie mir schien, mein Fieber war gestiegen, betrat kein Mann, sondern eine Frau mein Zimmer, die Mann hiess. Und der Kinderarzt war eine liebevolle Ärztin, die mein Haar streichelte und mich nicht nach meinem Namen fragte. Möglich, dass meine Verirrung wegen des Fiebers zusätzlichen Schub erhielt und nicht mehr einzugrenzen war. Meine Verabschiedung, «vielen Dank Frauen Arzt Doktor Herr Mann", meine gleichzeitige Frage, ob Frau Doktor Mann mehr ein Mann sei, löste lautes Lachen aus. Meine unverhältnismässigen Worte wurden als Folge der Erkrankung angesehen und nicht als Instabilität meines Gedankensystems. Wie, um Gottes willen, hätte ich denn 
verstehen sollen, dass der Arzt für Kinder, der Kind Arzt, eine Frau für Kinder war, und dass eine Frau Mann heissen konnte - insbesondere auch im Zusammenhang damit, dass ich selbst in diesen Dingen, die Anna betrafen, nicht sattelfest war. Ganz klug aus jenen Zusammenhängen bin ich bis heute nicht geworden. Möglicherweise ein kaum benennbarer, gänzlich unbedeutender Grund, um Medizin zu studieren. Und Anna? Anna habe ich, wie die Lockenhaare, hinter mir gelassen, nur hie und da meldet sie sich: verschmitzt lachend und mit langen Lockenhaaren (aber nur im Traum, nur dort, selten, ganz selten). 